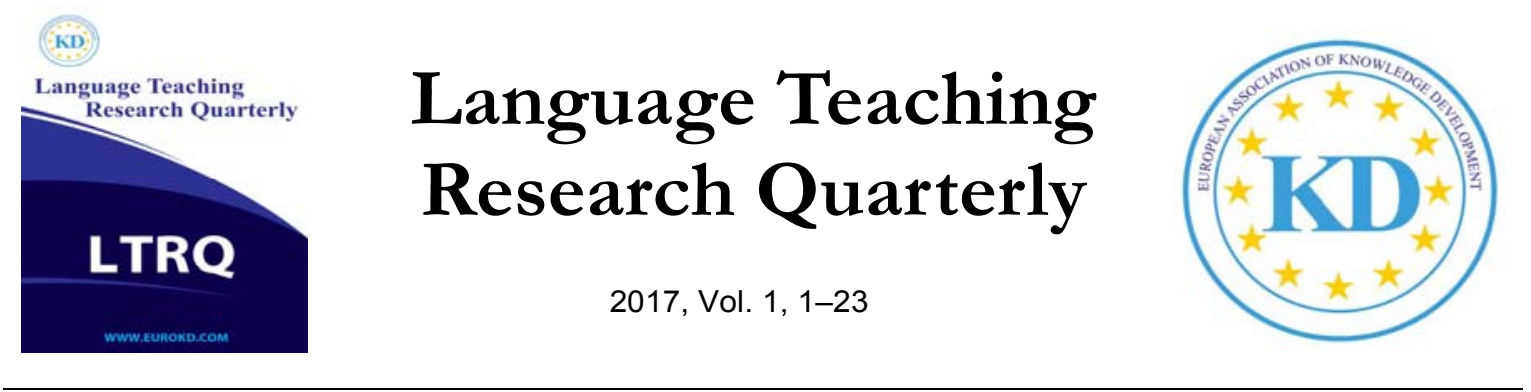

\title{
Does Dictionary Use Affect Iranian EFL Learners' Lexical Density in Writing?
}

\author{
Reza Abdi ${ }^{1, *}$, Habib Moazedi \\ ${ }^{1}$ Department of English Language, University of Mohaghegh Ardabili, Ardabil, Iran \\ ${ }^{2}$ Islamic Azad University, North Tehran Branch, Iran
}

\begin{abstract}
Received 2 February 2017 Accepted 7 April 2017
Abstract

An important, but rare question in EFL writing is whether learners should use dictionaries or not. The problematic state of this question prompted the present study. This study assesses research on the question of "does dictionary use affect Iranian EFL learners' lexical density or not". In order to answer the above question, a total of seventy four Iranian EFL intermediate learners (male and female aged from 17 to 26) from Nasr English Institute, Ardabil, Iran took part in this research study. The participants were high school and college students whose L1 was Azari-Turkish. They were appointed to three experimental groups and one control group randomly. Since this research explored the effect of dictionary use on learners' writing, the three experimental groups were labeled as EPD, PED and EED. The study had a pre-test, post-test 1 and post-test 2 design. All four groups took a proficiency test named Solutions Placement Test. ANOVAs proved their homogeneity $(F=.002, p=1.000)$. Then the participants completed three pieces of writing, each including a writing task with similar level and number of words but a different topic. Experimental groups had two treatment sessions after pre-test and they had a two-week interval after post-test 1 . During the test, experimental group one (EPD) used English-to-Persian dictionary, meanwhile, experimental group two applied Persian-toEnglish dictionary and finally, experimental group three took the advantage of English-to-English dictionary. Nevertheless, the compassion group received no dictionary and no treatment sessions. To fulfill the purpose of the study, a One-way ANOVA was applied to figure out the differences among the performance of the four groups. Although, there observed tangible improvement in the scores, the results ran counter to the expectations and showed no significant difference.
\end{abstract}

Keywords: Writing, Dictionary, lexical density 


\section{Introduction}

Writing is a very important skill which must be learned in order to effectively transmit new ideas and concepts. Writing can be considered as a complicated process. As a matter of fact, it can be very difficult to write in a foreign language. Meanwhile, a majority of EFL Iranian students have got difficulty learning this skill truly. "Meanwhile each task of writing is somehow both personal and individual process, it is also interactional and social, stating a culturally recognized aim, reflecting a specific kind of relationship, and proposing an engagement in a given population. This means that writing cannot be separated to a set of cognitive or technical capabilities or a system of regulations, and that taking up to write in a second language is not a matter of chances to compose and revise" (Hyland, 2003, p. 27). This process which is necessary for students to increase their writing competence have been investigated for a long time. Nation (2009) believes that writing is an activity that can be prepared by work in the other skills of speaking, listening and reading. This preparation can make it possible for words that have been used receptively to come into productive use. Flynn and Stainthorp (2006) compared writing with reading and pointed that writing is by far challenging than reading. This means that learning to write is very crucial than learning to read. Writing is a good instance of human knowledge processing in action. Writing has been a very complicated act that needs the orchestration of some of various activities at the same time and thereby places numerous needs on the cognitive system.

Despite the role writing plays in learning a foreign language, many of L2 teachers do not pay attention to the process of writing. Expressing one's feelings and points of view in written form in a foreign language and doing it with great correctness is an outstanding progress in today's world. But acquiring writing is too hard and its hardness gets deteriorated when it comes to a foreign language (Mehrdad, 2008). Although for many users writing has been confined to write short notes or homework, but the majority of it goes back to academic and professional settings (Kaplan, 2002).Carter and Nunan (2001) believe that there are two main differences in teaching second language writing and other language skills. Firstly, until 1970s, L2 writing was not considered as a language skill but, it was considered as a helping skill in language learning. Secondly, as the theory and practice of L2 writing teaching little by little developed, it used the way of US native English speaker composition theory.

"Most universities follow a modular system, which appears to promote examination-based approach learning. Consequently, students read and write to meet examination requirements and standards. Such a situation subjects them to cautious learning, which is neither motivating nor edifying for them" (Bilton \& Sivasubramaniam, 2009, p. 301). Under such discouraging conditions, students find it both easy to take up rote learning as a successful learning procedure. It is clear that their course work would look as a burdensome experience.

It would be advantageous to reflect more about theories of writing. Models that lead to the learning of L2 writing view it as a product or a process, a social or a cognitive activity, or a focusedon-form or a focused-on-content activity. Many studies have explored this significant area. (e.g., Ferris, 2010; Hyland, 2003). Attitudes that explain acquisition and development of L2 writing 
skills draw on L1 research and bring the main differences between L1 and L2 writing into light. With this in mind, the different concepts of writing can be grouped in three complementary and overlapping dichotomies (Hedge, 2000; Hyland, 2003; Llach, 2011). Writing is then understood as:

A product or a process

A cognitive or a social activity

A content-oriented or a form-oriented activity

The product-process distinction has led to the most heated debate. The features of both can clarify the point. The product approach to writing points that specific attention should be paid to language structure because the main focus is the written texts of learners. Accuracy is necessary, and grammatical and lexical knowledge is pre-requisite to writing. Writing includes taking the correct decisions regarding syntactic patterns, morphological inflections, vocabulary and mixing them all into a text. Consequently, grammatical and lexical errors are being considered as tinges of bad writing and lack of skills on the behalf of learner (Llach. 2011). With regard to this view, practicing and producing quantities of writing is the way in which learners learn to write. The main aim is to rehearse grammar and lexis, and to strengthen oral habits. Writing is not practical as an end itself but as a way for solidifying learners' knowledge of vocabulary and other grammatical structures (Hyland, 2003). Therefore, the goal of writing is firstly, practicing the vocabulary and grammar and secondly, helping develop writing ability for communicative purposes.

Llach (2011) points that process approach involves going through following stages: "planning and outlining the writing, generating ideas, writing several drafts, re-reading the text, revising, restructuring, editing and being able to call on any of these cognitive sub-processes whenever they are required" (p. 43). Furthermore, writing is conceived as a social practice and its processes should include discourse and contextual factors of language use. Another noteworthy point is that different genres must be considered. Namely, how to write a report, article or an academic paper, English for Specific Purposes (ESP) and English for Academic Purposes (EAP) are rooted in this approach.

Process writing includes theories which emphasize the content orientation of the composing process. So the concepts stated in this way are at least as important as the accuracy of the discourse (Hyland, 2003). In contrast, other viewpoints of language are form-oriented, that is to say, they focus on sentence and paragraph building, and consider writing as a matter of arranging words within sentences and paragraphs. Hedge (2000) concedes that it seems to be the sensible way forward for teachers to apply both approaches to develop those needed features of students. Moreover, the importance of each principle depends on the needs of student writers. For instance, a process approach is appropriate for young learners since it develops effective strategies. Totally, every teacher should develop a methodology to integrate students' specific needs and a way to the teaching of writing.

When dealing with L2 writing skills, two essential issues deserve specific attention: L1 literacy and L2 proficiency. It seems that L2 writing involves the same composing processes as L1 writing. However, some differences make the issue more appealing. The first crystal-clear difference is 
that it enjoys a fully developed linguistic system and L1 literacy abilities. Nevertheless, L2 learners' command of the 12 is underdeveloped and there is a plethora of degrees of variability in the L2 proficiency among learners. The basic process shaping the relationship between L1 and L2 literacy skills is the phenomenon of transfer (Grabe, 2003: as cited in Llach, 2011). Learners use the skills that they have achieved for reading and writing in L1, when learning to write in L2. So, learners transfer these skills and processes they apply in L1 writing to L2 writing. While L1 and L2 writing follow the same processes, L2 writers spend less time in these steps. The other difference is that learners make use of their L1 when composing in the L2. In addition, this is done to compensate for lexical gaps with L1 vocabulary items or to produce new viewpoints by using L1 content knowledge. Llach (2011) believes that "In short, writing contributes to vocabulary development, and vocabulary use in writing enhances the quality of the written text" (p. 46).

Many people have a primary understanding of writing concepts, but want to learn to more. One important way is by providing feedback. During last decade, L2 teachers and researchers have studied written corrective feedback (WCF) in the L2 writing pedagogy. Evans, Hartshorn, McCollum, and Wolfersberger (2010) found that although beneficial writing skills are necessary for the success of L2 learners, they confront with special difficulties in making these skills better. This is directly relevant to their ability to produce writing that is linguistically acceptable. The effectiveness of error correction is of great importance for the theory and practice of writing instruction. With regard to error correction, the so-called Big Question is that is correction useful for the development of accuracy or not. Truscott $(2004,2007)$ claimed that the rationale behind this question is the comparison between the writing of the students who have received correction and others who have received little or none. The efficacy of correction raised different opinions and conclusions, and also led to a big number of studies (e.g., Bitchener \& Knoch, 2010; Bitchener, Young, \& Cameron, 2005; Bruton, 2010, Chandler, 2003; Ferris, 2003; Lalande, 1982; Paulus, 1999; Truscott, 1996, and Tuzi, 2004). Rather than interpreting the opposing results as a demonstration of the effectiveness or ineffectiveness of corrective feedback on form, Guénette (2007) examined these studies from a various aspects. He suggested that findings can be appointed to the research design, methodology, and some uncontrollable external variables. He pointed that this uncertainty had many consequences both for teachers and researchers.

Ellis (2008) has investigated the issue from a different perspective. His typology diagnoses two sets. Those relating to strategies for providing feedback (for instance, direct, indirect, or metalinguistic feedback) and those relating to the students' reaction to the feedback (for instance, revision and attention to correction). This categorization has been covered in preceding part. Direct CF has the advantage that it is clearly pleasant if the learners do not know what the plausible form is (i.e. they cannot self-correct the error). However, a disadvantage is that it just provides learners the correct form of the error and there may be minimal progress and long-term learning on the part of the learner. As already noted, indirect feedback is preferred to direct feedback because it leads to guided learning and problem solving and finally encourages students to reflect about linguistic forms. He contends that indirect feedback where the exact location of errors is not identified might be more effective than indirect feedback where the place of error is highlighted as students would 
have to engage in deeper processing. The last option is reformulation which tries to provide learners with a resource that they can apply correcting their errors but the learners are responsible for the last decision about whether and how to correct.

Truscott had a strong view against the effectiveness of error correction on students' writing. In 1996 he composed a review article arguing that all types of error correction of L2 student writing are not only ineffective, but also harmful and should be deleted. Ferris (2004, as cited in Guénette, 2007) claimed that currently we are unable to verify that error correction is effective, as the current research basically incomparable due to deficits in design. Ellis (2008) believes that while feedback is very important in L2 writing, the research literature is not positive about its role in L2 development.

\section{Lexical density}

"The term lexical density was originally coined by Ure (1971, as cited in O'Loughlin, 1995) to provide a rubric of the relationship between the number of words with lexical as opposed to grammatical properties as a percentage of the total number of words in a text"(O'Loughlin, 1995, p. 28). Lu (2012) recognizes lexical density as an important construct in L2 teaching and research. Thus, it is interrelated to the learners' abilities to communicate effectively in both spoken and written forms. The importance of the lexical density has led to many studies (e.g., Henrichs, 2010; Thonney, 2011). Henrichs (2010) concedes that the lexical density of a text shows the number of words with a lexical function compared with a grammatical function. This is described as a percentage of the number of lexical words over all words in a text. He also believes that every speaker in an academic situation is expected to have accurate knowledge about a specific topic of discourse. So, to convey information in an explicit manner, lexical words are needed. Simply stated, a high lexical density is used as a feature of academic register. Furthermore, he claims that the number of count words in comparison to the total number of words is an indication of the amount of information that is packed into the sentence, so, this measure must be regarded as an approximation of lexical density.

Ure (1971, as cited in O'Loughlin, 1995) pointed that lexical density is a true measure of the degree of 'literacy' versus 'orality' in a context. She found that, with only a few exceptions, spoken texts had a lexical density of less than $40 \%$ (ranging from $24 \%$ to $34 \%$ ) and the written texts had a density of greater than $40 \%$ (ranging from $36 \%$ to $57 \%$ ).

Another main issue within the area of vocabulary and writing is lexical errors. They are specific types of errors which have received little attention. Morphology and syntax have been considered to be more systematic and rule-governed than the lexis. Llach (2011) believes that there are some complex and irregular relationships among elements in the lexicon, and the context and the communicative situation are necessary for determining the correct use of the lexical system. Llach (2011) states that the term "lexical error" is used to refer to the deviations in the learner's production of the L2 norm with regard to the use in production and reception of lexical items. All of us know what word is; however, we cannot provide a formal definition. Hence, the terms "word"

WWW.EUROKD.COM Doi: 
and "lexical unit", and "lexical items" are used interchangeably to refer to the smallest semantic unit. Totally, a lexical unit includes a single word or morpheme or of several words.

Another distinction is made between grammatical and lexical words. The former includes prepositions, articles and conjunctions, whereas words belonging to the class of nouns, verbs, adjectives make up the latter one. Furthermore, lexical errors will affect lexical words, while errors affecting grammatical words, will be studied as grammar errors. Clear definitions of "lexical error" can pave the way for more discussions. The definition of the term "lexical error" is based on the concept of lexical competence. Also identifying lexical errors is not always an easy task. "Lexical competence mentions not only semantic knowledge, but also morphological, syntactic and pragmatic knowledge" (Llach, 2011, p. 72). It can be concluded that "knowing a word" means knowing how to apply it correctively with other words and texts. So, the communicative and situational context must be considered. There is a lack of clear definition of "lexical errors" in the research. "Most studies are concerned with identification, description, interpretation and classification of lexical errors, and not with providing an explicit definition" (Llach, 2011, p. 72).

There are two kinds of inconsistencies in the literature. The first one is a polysemy of meanings attached to the term "lexical error" and the second one is a polysemy of terms referring to the phenomenon of deviating from the lexical norm in form or meaning. In polysemy of meanings, different researchers understand different things under the term "lexical error". On the other hand, many researchers allude to "lexical error" as a major term for serving as a healing for several other classes of errors. In addition, Llach (2011) asserts that the term "lexical error" includes several subcategories that classify lexical errors regarding the different criteria that can be descriptive, etiologic, semantic, epistemic, psycholinguistic, and process-oriented. This classification needs more discussion in detail and it is far from the area of the present study. Figure 1 shows a summary of the tendencies observed in the treatment of the term "lexical error".

It should be borne in mind that lexical errors can be counted on as evidence of vocabulary acquisition. Lexical errors play an important role in SLA due to the fact that they provide insights into the process of L2 vocabulary acquisition and show problematic fields in acquisition and learning phases (Llach, 2011). To put it differently, lexical errors help learners and researchers identify the gaps in lexical repertoire and realize the underlying processes in the L2 vocabulary acquisition. They also help students find problematic areas in L2 vocabulary acquisition. They provide learner with the structure of the mental lexicon in L2 and more about lexicon development. Moreover, lexical errors show the patterns of associative and synonymy relationships. Furthermore, there are two other important issues. Form-oriented lexical errors reveal that words which are formally similar are stored together. On the contrary, meaning-oriented errors point to semantic links between words, that is to say, semantically related words are stored together (Llach, 2011). 


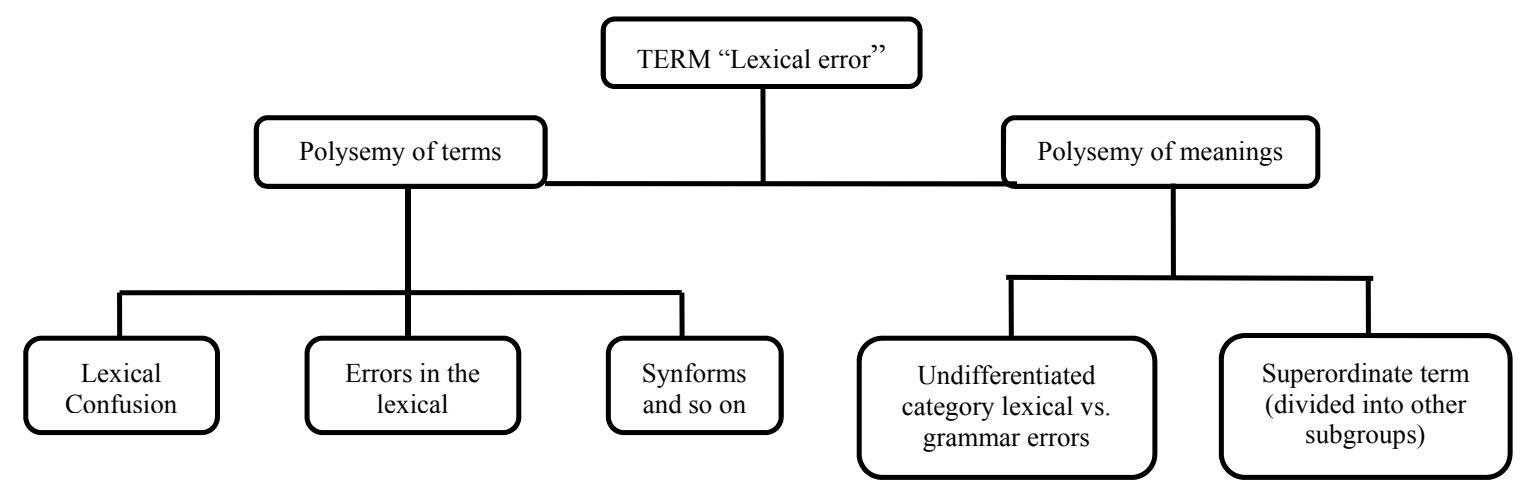

Figure 1. A summary of the tendencies observed in the treatment of the term "Lexical Error"

Also, lexical errors can be debated from the perspective of communication and educational context. In the former, "words are the means to express meanings and, accordingly, they are the basic element of verbal communication" (Llach, 2011, p. 95). In the latter, vocabulary is proved to be an important predictor of linguistic competence and there is common agreement that vocabulary is crucial to varying areas of language proficiency such as writing and reading. In sum, identification of "lexical errors" permits the educationalists to find the frequent lexical errors and draw conclusions about the pedagogical implications of these lexical errors in L2 learning (Llach, 2011).

\section{Dictionary use}

One area of current discussion with regard to the learning of second or foreign language (L2) writing has concentrated on whether L2 learners should be permitted to use dictionaries or not. Language teachers and learners are getting confused about the role of dictionaries in L2 learning. Teachers discourage students from using dictionaries in most English classrooms and avoid giving instructions on how to use dictionaries, though, it is widely accepted that many learners use dictionaries on a frequent basis. Perhaps due to the fact that dictionaries are considered as tools for increasing students' tendency for learning individual words (Karbalaei \& Talebi, 2011).

The dictionary, according to Kirkness (2004, as cited in East, 2008) is defined as an essential source of information on language for all members of literate societies who might have questions on any aspects of the form, meaning, and use of the words in languages. He also claims that L2 learners consider bilingual dictionaries to continue to be the most-used reference book at all learning levels. Ilson (1985) thinks of the dictionary as the most significant book about language. For Ilson, its importance lies in its authority to settle disputes. Many studies suggest that dictionaries for language learning have been largely neglected in books and papers. In 1999, Asher studied dictionary policy in schools. Later, he investigated teacher's classroom practice and their ideas about the effects of dictionaries on students' pattern of learning. Chambers (1999) studied the students' views about dictionary availability in curricula. It seemed that many teachers 
supported having dictionaries in the examination because they were authentic and helpful, and led to greater self-reliance and autonomy in learners (East, 2008). It would therefore be advantageous to talk more about the value of dictionary in foreign language learning. In one hand, using a dictionary is conceived as an authentic activity in the context of L2 students' learning and it may be discussed that using dictionaries in learning and writing is valid (Bachman \& Palmer, 1996; Wiggins, 1989). On the other hand, when the dictionary is understood not only as an authentic tool but also as a supportive tool, there are more reasons to take up its use or non-use in tests carefully. This ongoing debate has been heated by different perspectives on the purpose of L2 learning and writing. Dictionaries in writing may be viewed more positively by those who support dynamic writing and more negatively by those who take a more traditional viewpoint. In the first one, the communicative writing proficiency construct is described more broadly as an authentic reflection of writing as a process, including the strategies for increasing the communicative impressiveness of the messages. As such, the use of dictionary is arguably a valid part of the construct. In the second one, the communicative writing proficiency construct is understood more narrowly as writing performance.

In the late 1990s, the UK's qualifications and curriculum authority (QCA) - the governing body for developing national curriculum for schools - decided L2 students should be allowed to take bilingual dictionaries into the examination with themselves as support resources. When the initial decision to introduce bilingual dictionaries into school curriculum was made there was a plethora of research activity about dictionaries (East, 2008). If we consider the results taken from this range of research, we realize that, on the bright side, many teachers are in favor of having dictionaries in the examination; they are helpful and enhance learner autonomy, self-evidence, and confidence. As previously mentioned, Asher's (1999) study also proved that a good number of teachers valued the authenticity that using dictionaries brought to language learning and language use. On the negative side, students' inability to use dictionaries appropriately and the need for training in dictionary skills became a concern. Teachers were worried that students might overuse the dictionary, look up items word by word, produce inaccurate language, and waste time. "They were also concerned that students might be less likely to commit words to memory if they knew they had access to a dictionary in the examination" (p. 3, East, 2008).

Barnes et al (1999, as cited in East, 2008) showed that allowing a dictionary in the test room was making it hard to get student to do any learning homework properly. Also they showed that the majority would use dictionary as an excuse not to learn vocabulary. The students themselves conceived dictionaries as helpful devices for understanding and translating ideas into the target language more easily. Even, they thought that dictionaries would help them in the face of examination with greater confidence. Hurman and Tall (1998) undertook a very different kind of investigation in writing examination, one taken with, and one without a dictionary. Certainly those who had been allowed the dictionary in their examinations were generally positive about it. Even some students saw dictionary as a "life-saver", a useful resource to check up a few keywords without which they would have been lost. Dictionaries were very effective for checking words. Their use was authentic and they helped with the continued use of authentic texts, both in class 
and in the examination (East, 2008). He also believed that not allowing dictionaries to students caused some stress and resulted in much more emphasis on the decontextualized rote-learning of lists, something that students certainly appeared to detest. On the plus side, dictionaries promoted:

Authenticity

More independence

More flexibility for answering questions

More confidence

On the minus side, there was concern over:

Taking long time to use dictionaries

More dependence on the dictionary

Not taking sufficient time to learn vocabulary

Misuse of the dictionary

The other issue regarding this is the usefulness of dictionaries in assessments, particularly in writing assessment. The structure of writing proficiency on a framework of communicative competence tries to help language learners use language to create meaningful communication in authentic and real life contexts. If using a dictionary is an authentic part of real world writing and it its use supports the test takers, why we should outlaw it from the tests? The answer to this question reveals the complexity of this issue (East, 2008). However, students use and misuse of the dictionary and different assessment paradigms make the question of different kinds of dictionaries in assessment, particularly in writing.

We go on to consider two main types of dictionary available to the L2 learner - monolingual and bilingual dictionaries - and weigh up their relative merits and demerits. Many studies have compared bilingualized dictionaries with other types (Bruton, 2007; Chambers, 1999; Karbalaei \& Talebi, 2011; Laufer \& Hadar, 1997; Maghsoudi, 2010; Xu, 2010). Bilingualized dictionaries may be the way to go in the future. A bilingualized dictionary is a mediocre between monolingual and bilingual dictionary. Laufer and Hadar (1997) define dictionary as a mixture of a monolingual dictionary, with the same number of entries and their translation into the target language. Thompson (1987) conceives that monolingual dictionaries have a very crucial role to play at most advanced levels. "As a consequence, it is often perceived that monolingual dictionaries are the most appropriate pedagogical tools regardless of the circumstances" (East, 2008, p. 16). Some teachers think that monolingual dictionaries do the best and in the reverse order, some others believe that bilingual ones are more useful. But for low level students bilingual dictionaries can do all the useful things than monolingual ones. East (2008) points that confident and effective use of bilingual dictionary promotes learners' autonomy. That is to say, learners can start from their L1 understanding of a word to search its $\mathrm{L} 2$ equivalent $(\mathrm{L} 1 \rightarrow \mathrm{L} 2)$, or can check the L1 meaning of a word (L2 $\rightarrow \mathrm{L} 1$ ). Bilingual dictionaries may be needed for checking items in generating a written response, and also necessary for completing the response adequately. Hunt and Beglar (2005, as cited in Maghsoudi, 2010) believe that the strengths of bilingual dictionaries are:

Improving the reading comprehension of L2 learners

Assisting vocabulary learning at all levels of proficiency 


\section{Encouraging translation}

Fostering one-to-one correspondence of words between two languages

On the contrary, monolingual dictionaries are used for building and elaborating learners' vocabulary knowledge by providing information about meaning and grammar. "Basically, the monolingual entry can provide a great plenty of detailed and precise information about idiomatic usage, common collocations and connotations" (Maghsoudi, 2010, p. 317). He also points that due to impossibility of combination of useful properties of these dictionaries, there is a significant interest in the new bilingualized compromise dictionaries. A bilingualized entry involves: L2 definitions, information about L2 sentences, and L1 synonyms. Also, these types provide translations. Laufer and Hadar (1997) believe that using bilingualized dictionaries is more helpful than using bilingual or monolingual dictionaries. Because they are more flexible, learners of all levels can depend on the L1 translation. Different ideas about use or non-use of dictionaries have led to hot debates. Some teachers discourage students from consulting dictionaries and believe that they do not help students to understand vocabulary in context and some others claim that students overuse dictionaries at the expense of developing the ability to guess from context and selfconfidence. "While others advocate only using the target language and are concerned that bilingual dictionaries used for word translations will adversely affect student comprehension at the sentence and discourse level" (Maghsoudi, 2010, p. 318). East (2008) has asserted following points as conclusion:" Bilingual dictionaries are potentially supportive tools for L2 learners - they help them to make up for gaps in their knowledge. Bilingual dictionary use is authentic - L2 users use them in the real world if they do not know or cannot understand something. The ideal assessment of writing proficiency will aim to mirror real world practice as authentically as possible" (p. 34).

Hurman and Tall (1998, as cited in East, 2008) were interested in obtaining comparative test score evidence and investigated the difference that bilingual dictionaries made in tests. In a study conducted with over 1000 participants they utilized repeated measures design to look at the effect of using bilingual English/French dictionary on writing at the two levels of the examination. East (2007, as cited in East, 2008) used the number of look-ups in a statistical calculation to determine if there was any relationship between frequencies of dictionary use and test scores. In another study, Bishop (2000, as cited in East, 2008) found that two out of three test takers reported that they used the dictionary no more than five times to locate words when writing.

Matsumoto and Prichard (2011) viewed the dictionary use from another perspective. They studied the effect of lexical coverage and dictionary use on L2 reading comprehension. They believed that the impact of dictionary use on lexical coverage has largely been neglected. Some teachers believe that less proficient learners should read graded materials before going to authentic texts and when focusing on authentic texts, they should guess the meaning of unfamiliar words from the context, so, many teachers discourage the use of dictionaries altogether in the reading classroom. On the other hand, some others state that dictionary use can result in better reading comprehension. Therefore, how dictionary use affects lexical coverage to influence reading comprehension needs to be explored. Dictionary use may not help the learners with low lexical range to comprehend the text because dictionary use needs numerous cognitive resources and using 
a dictionary may overwhelm learners. Learners should find the best definition of the words which applies to the context, but understanding the context necessitates knowledge of most of the other words in the essay. It could be concluded that the use of dictionaries can enhance comprehension for learners of all levels. However, the number of look-ups depends on the learners' lexical coverage (Matsumoto \& Prichard, 2011).

In another study by Tono (2000), the effects of different types of electronic dictionary on L2 learners' productive and receptive tasks were studied. Electronic dictionaries have been accessible to learners recently and their educational benefits are outstanding. But it seems that they have more advantages over paper (or hard-copy) dictionaries. In spite of the doubt over this issue, however, many students prefer to have electronic dictionaries because they are faster and easier in looking up the words. Tono (2000) also believes that "from lexicographical viewpoints, one of the differences between hard-copy dictionaries and electronic dictionaries is that the former has only a linear, non-hierarchical micro-structure, while the latter has a hierarchical, layered presentation. The paper dictionary has its own micro-structure, but it must inevitably present all the information in a linear order on the same level. Electronic dictionaries, on the other hand, can handle information in a more flexible way" (p. 855).

Benoson, Sim and Weiss (1984) investigated the effect of dictionary usage On EFL test performance compared with student and teacher attitudes and expectations. The results of the study had some assumptions. These assumptions may be summarized as follows:

If permitted, all students prefer to have the opportunity at using a dictionary during a test. Using a monolingual/bilingual dictionary would significantly raise examination scores. Using a dictionary would increase the time taken to complete a test. Low-proficiency students would use the bilingual dictionaries more than high-proficiency students. Because of having larger vocabulary, more proficient students would use the dictionary less than low-proficiency students.

Prichard (2008) analyzed the dictionary use from another aspect. He stated that selective dictionary use may cause to improved comprehension and efficient vocabulary development. Vocabulary is one of the most superb parts of second language reading comprehension. When learners confront with an unknown word, they can either ignore the word or consult a dictionary. Classic grammar-translation methods have focused on decoding text and using dictionaries more. However, current communicative practices encourage learners to grasp the meaning of unknown words from context (Prichard, 2008). However, Bogaards (1998, as cited in Prichard \& Matsumoto, 2011) pointed that learners liked to look up the correct definition of words in the dictionary rather than guessing the meaning of unfamiliar words from context. In fact, L2 dictionary use improves reading comprehension and leads to lexical development.

Application of new technologies such as handy-electronic dictionaries, online dictionaries and marginal glosses may affect dictionary use, because looking up for unknown words takes less time and distracts the reader from the text to a lesser degree. There are numerous factors that affect dictionary use. Most learners do not look up words by chance. That is to say, if getting the meaning of unknown words, learners are not desired to consult a dictionary. Another influencing factor is 
task. For instance, readers have to know the meaning of each word in a translation task, while readers of general reading can ignore unknown words (Prichard, 2008).

There are some merits and demerits about the use of dictionaries. Finding words may amplify learners' receptive vocabulary and can also enable comprehension. Since it takes longer time to read when using a dictionary, high-proficiency learners' benefit less from dictionary use. It is easier and faster to look up words in online or electronic dictionaries; however, it may decrease vocabulary retention. Furthermore, learners should use dictionaries when reading a text above their level to reach the comprehension threshold. In fact, using a dictionary more than real needs may lead to an inappropriate use of study time and inefficient retention. As concluding remarks, Prichard (2008) claimed that some learners might benefit from instruction on selective dictionary use and they may use them to realize the gist of a passage and evaluate the frequency and usefulness of unknown words.

\section{Method}

\section{Participants}

A total of seventy four EFL Iranian intermediate learners (male and female aged from 17 to 26) from Nasr English Institute participated in this study. They were high school and college students whose L1 was Azari-Turkish. They had received three hours of English language teaching twice a week for three years. They were classified into four groups randomly: G1 as control group $(\mathrm{n}=19)$, G2 as experimental group $1(\mathrm{n}=19), \mathrm{G} 3$ as experimental group $2(\mathrm{n}=18)$, and $\mathrm{G} 4$ as experimental group $3(n=18)$. Since the study investigated the effect of dictionary use on EFL learners' writing, the three experimental groups were labeled respectively as: English to Persian dictionary (EPD), Persian to English dictionary (PED), and English to English dictionary (EED). All three experimental groups used dictionary but the control group did not use any dictionaries.

In order to get assurance as to the homogeneity of the learners, I administered a proficiency test and put the scores into a one-way ANOVA. The result showed that there was no significant difference across the four groups $(F=.002, p=1.000)$.

\section{Materials and instruments}

All the four groups completed a proficiency test, a pre-test, post-test 1, and post-test 2. The proficiency test, Solutions Placement Test (Oxford Publications, 2007) was used to evaluate participants' general knowledge of language. The test consists of 50 multiple-choice questions which assess students' knowledge of grammar and vocabulary from elementary to upperintermediate levels, a reading text with 10 graded comprehension questions, and an optional writing task that examines students' ability to write. Every correct response gets one point, adding up to a maximum of 70 points. The top score is 70 and the minimum scores are between 31 and 44 for pre-intermediate level. The total time for 50 multiple choice questions and the reading task is 45 minutes and the writing task can be done in 20 minutes. The next three tests (pre-test, posttest 1 , and post-test 2 ) were writing tasks. They were three general subjects to compose three pieces of writing. Students had to write 150 words within 50 minutes. East (2007) argued that 50-minute 
time-frame is sufficient to elicit a rateable sample of language. To ensure that the three titles were as similar as possible in terms of complexity of language, each was created to contain a similar number of words which were selected from East (2007) and Longman Preparation Course. The subject of pre-test was " Languages in Iran: These days all school students should learn at least ONE foreign language in school. Are you also of this opinion? ". In addition, the subject of posttest 1 was "Mass Tourism: "These days many tourists from many countries visit Iran, and that is good for the country". What do you think? At the end, participants had the following topic for their post-test 2:" Some people prefer to work for a company, while others prefer to work for themselves. Discuss the advantages of each. Then indicate which you prefer and why".

Because participants were free to choose their own dictionaries, they were encouraged to use the one with which they had previously developed a level of familiarity. In all, five different types of dictionary were used. Oxford Learner' Dictionary was the most popular one. All the participants were informed to take their own dictionaries to testing sessions. Table 1 shows the dictionaries used in the study.

Table 1. Dictionary types used by participants

\begin{tabular}{lc}
\hline 1 & Oxford Learners' Dictionary \\
2 & Longman Dictionary of American English \\
3 & American Word Power Dictionary \\
4 & Haim Dictionary \\
5 & Millennium Dictionary \\
\hline
\end{tabular}

\section{Procedures}

Two weeks before to the pre-test, the participants were given information about the study and had the opportunity to ask questions before beginning the experiment. The next week, a proficiency test was administered to the participants in order to satisfy the homogeneity concern and meet the issue of readiness of the participants. They were required to do it in 30 minutes. On the first day, the pre-test, which involved a general writing, was administered to all participants in four groups. The treatment sessions commenced a week later. During, treatments, the students were given papers about dictionary use and they were instructed how to use dictionary (For instance, meaning, gender, grammar, use in context, spelling, synonyms, pronunciation, etymology, feminine forms, verb forms, plurals, and register) by the same teacher in experimental and control groups. During the study, control group had a placebo; that is, they had only their own routine schedule without any treatment and dictionary. They only had the pre-test and two post-tests

Two independent raters, both experienced with M.A degree in English Teaching, were asked to rate the tasks. In order to ascertain the accuracy of scoring, the rubric drawn on Canale and Swain's (1980) theoretical framework of communicative competence were used. The scoring rubric enabled raters to differentiate between eight levels of performance (from 0 to 7 ) across five separate facets of the writing. Raters were given a copy of the scoring rubric and instructions for how the rating process should be carried out. Immediately after the task, the writings were copied and the participants were required to highlight or underline in their original writings words looked up in the dictionary. East (2008) believed that underlining is a good way to enable quantitative and qualitative analyses of how participants use the dictionary. Although the number of look-ups is not 
within the scope of this study, but its findings showed a gain in the number of look-ups from pretest to post-test 2 . Then the copied writings were given to the raters and they were not informed which essays have been written in which condition. In the fourth and eighth weeks, participants were required to write essays with different subjects as post-test 1 and post-test 2 . To provide some measures of the intra-rater reliability of the scoring, the two raters were invited back about two weeks after the original rating to re-rate 20 essays to discuss the discrepancies.

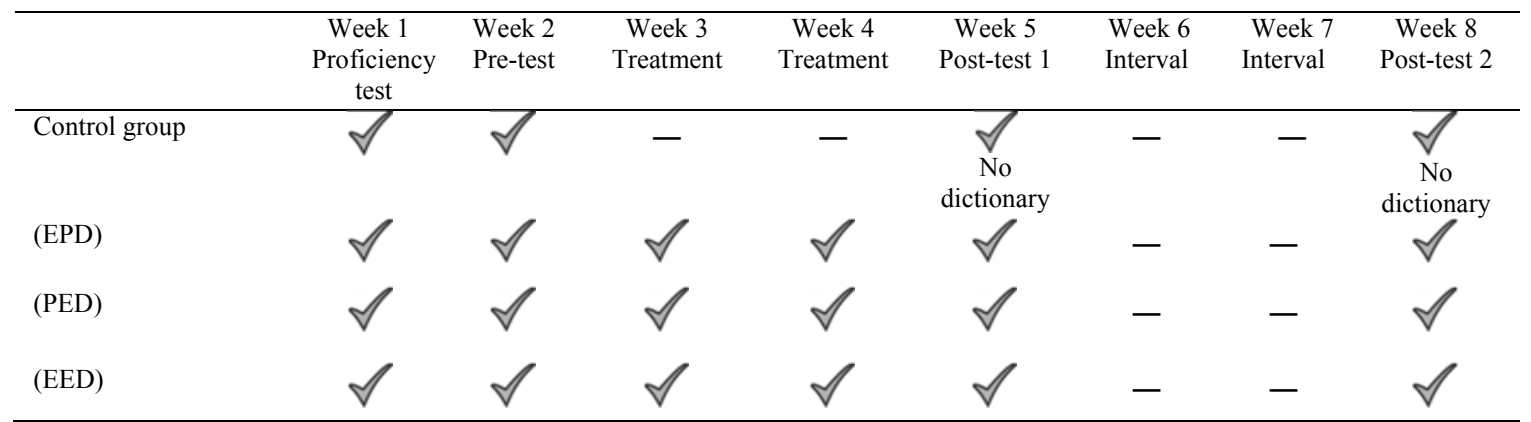

Figure 2.The design of the study.

$\mathrm{EPD}=$ English to Persian Dictionary, $\mathrm{PED}=$ Persian to English Dictionary, and $\mathrm{EED}=$ English to English Dictionary.

\section{Data analysis and results}

In this study, descriptive statistics were used for the proficiency test scores, which exhibited mean and standard deviation of the scores. Then a one-way ANOVA was run to ensure the homogeneity of the participants. Additionally, One-sample Kolmogorov Smirnov Test showed the normality of the test distribution. Following this, two descriptive statistics were calculated for post-test 1 and post-test 2. At the end, two one-way ANOVAs were run for the post-test 1 and post-test 2 respectively.

First and foremost, descriptive statistics for the proficiency test scores of the four groups were calculated which is shown in Table 2 . Then, in order to ensure that all students began the study with similar language proficiency, an analysis of variance (ANOVA) was performed on the scores obtained from proficiency test. Results are presented in Table 3.

Table 2

Descriptive Statistics for the Proficiency Test Scores across the Four Groups

\begin{tabular}{lcccccccc}
\hline & $\mathrm{N}$ & Minimum & Maximum & Mean & Median & Variance & Range & Std. D \\
\hline Control & 19 & 31.00 & 59.00 & 43.5263 & 42.0000 & 68.708 & 28.00 & 8.28900 \\
EPD & 19 & 31.00 & 59.00 & 43.3158 & 44.0000 & 63.561 & 28.00 & 7.97254 \\
PED & 18 & 31.00 & 57.00 & 43.4444 & 41.5000 & 79.908 & 26.00 & 8.93916 \\
EED & 18 & 31.00 & 57.00 & 43.5000 & 43.000 & 68.147 & 26.00 & 8.25512 \\
Total & 74 & 31.00 & 59.00 & 43.4459 & & & & 8.19145 \\
Valid N & 74 & & & & & & & \\
\hline
\end{tabular}

Table 3

One-Way ANOVA Results for the Proficiency Test Scores of the Four Groups

\begin{tabular}{lccccc}
\hline & $\mathrm{SS}$ & $\mathrm{df}$ & $\mathrm{MS}$ & $\mathrm{F}$ & Sig. \\
\hline Between groups & .497 & 3 & .166 & .002 & 1.000 \\
Within groups & 4897.787 & 70 & 69.968 & &
\end{tabular}


Total 4898.284 73

As it can be observed from Table 3, the Sig. value is 1.000 (and $F=.002$ ), which is greater than alpha level of .05. Since the Sig. is greater than alpha level, it was taken as a sign of homogeneity of participants in terms of general knowledge. Then, these four homogenous groups of learners were randomly labeled as the control group $(n=19)$, experimental group 1 or EPD $(n=19)$, experimental group 2 or PED ( $n=18)$, and experimental group 3 or EED ( $n=18)$. Then the pre-test was administered to all four groups and the scores were analyzed.

Inter-rater reliability measures were also predicted for pre-test, post-test 1 and post-test 2 . So, two raters were invited to rate the writings with the aim of ascertaining the accuracy of scoring. Second rater scored a sample of 20 writings from the pre-test and post-test 1 and 2 . The sample came approximately equal. Running Cronbach's Alpha, it was revealed that inter-reliability for rater 1 and rater 2 were .827 and .833 , respectively. The results of the inter-rater reliability proved that all writing scores are reliable and the study can be pursued.

Now it is the time to get to the question which motivated the study. The question was whether dictionary use affects EFL learners' lexical density or not. As it was said earlier, lexical density can be measured by the ratio of the number of lexical words to the total number of words in a text (Ure, 1971). So with this in mind, the lexical density of the tasks of the four groups in pre-test, post-test 1, and post-test 2 was calculated. At first, the normality of the lexical density (LD) was measured by One-Sample Kolmogorov-Smirnov Test which is exhibited in Table 4. Then the descriptive statistics of lexical density in scores of pre-test was estimated that is shown in Table 5.

Table 4

One-Sample Kolmogorov-Smirnov Test for Lexical Density

\begin{tabular}{lllll}
\hline & & Pre-test & Post-test 1 & Post-test 2 \\
\hline $\mathrm{N}$ & & 74 & 74 & 74 \\
Normal Parameters & Mean & 46.3514 & 48.1486 & 47.9324 \\
& Std. Deviation & 5.48081 & 5.62938 & 4.48233 \\
Most Extreme Differences & Absolute & .075 & .074 & .114 \\
& Positive & .075 & .047 & .074 \\
& Negative & -.056 & -.074 & -.114 \\
Kolmogorov-Smirnov Z & & .641 & .633 & .982 \\
Asymp. Sig. (2-tailed) & & .806 & .817 & .290 \\
\hline
\end{tabular}

Test distribution is normal.

Table 5

Descriptive Statistics for the Lexical Density in Pre-test

\begin{tabular}{lcccccccc}
\hline & $\mathrm{N}$ & Minimum & Maximum & Mean & Median & Variance & Range & Std. D \\
\hline Control & 19 & 40.00 & 57.00 & 46.2632 & 46.0000 & 17.205 & 17.00 & 4.14785 \\
EPD & 19 & 36.00 & 53.00 & 45.3158 & 46.0000 & 22.228 & 17.00 & 4.71467 \\
PED & 18 & 37.00 & 57.00 & 46.2778 & 47.0000 & 31.154 & 20.00 & 5.58154 \\
EED & 18 & 33.00 & 65.00 & 47.6111 & 47.000 & 53.193 & 31.00 & 7.29334 \\
Valid N & 74 & & & & & & & \\
\hline
\end{tabular}


A closer look at the mean score in Table 5 reveals that participants in all groups showed improvement from pre-test to post-test 1 . However, they did not show any gain from post-test 1 to post-test 2. Simply stated, the mean and the standard deviation for all groups on pre-test are 46.3514 and 5.48081. For post-test 1, the mean and the standard deviation are 48.1486 and 5.62938 and eventually, the mean and the standard deviation for post-test 2 are 47.9324 and 4.48233. Table 6 and Table 7 below, exhibit the descriptive statistics for the lexical density in post-test 1 and posttest2.

Table 6

Descriptive Statistics for the Lexical Density in Post-test 1

\begin{tabular}{llccccccc}
\hline & $\mathrm{N}$ & Minimum & Maximum & Mean & Median & Variance & Range & Std. D \\
\hline Control & 19 & 41.00 & 57.00 & 49.4737 & 49.0000 & 19.041 & 16.00 & 4.36359 \\
EPD & 19 & 34.00 & 60.00 & 47.5789 & 48.0000 & 47.035 & 26.00 & 6.85821 \\
PED & 18 & 38.00 & 56.00 & 47.1667 & 47.0000 & 20.500 & 18.00 & 4.52769 \\
EED & 18 & 37.00 & 59.00 & 48.3333 & 43.000 & 42.235 & 22.00 & 6.49887 \\
Valid N & 74 & & & & & & & \\
\hline
\end{tabular}

Table 7

Descriptive Statistics for the Lexical Density in Post-test 2

\begin{tabular}{llccccccc}
\hline & $\mathrm{N}$ & Minimum & Maximum & Mean & Median & Variance & Range & Std. D \\
\hline Control & 19 & 42.00 & 51.00 & 48.0000 & 49.0000 & 6.000 & 9.00 & 2.44949 \\
EPD & 19 & 35.00 & 57.00 & 47.6316 & 49.0000 & 33.579 & 22.00 & 5.79473 \\
PED & 18 & 42.00 & 56.00 & 47.77784 & 47.5000 & 12.771 & 14.00 & 3.57369 \\
EED & 18 & 40.00 & 58.00 & 48.3333 & 49.5000 & 31.294 & 18.00 & 5.59411 \\
Valid N & 74 & & & & & & &
\end{tabular}

Considering Table 8 below, it can be concluded that there is no statistically significant difference in the performance of four groups on pre-test $(F=.535, p=.660)$

Table 8

One-Way ANOVA Results for the Pre-test Scores of the Lexical Density

\begin{tabular}{lccccc}
\hline & SS & df & MS & F & Sig. \\
\hline Between groups & 49.187 & 3 & 16.396 & .535 & .660 \\
Within groups & 2143.678 & 70 & 30.624 & & \\
Total & 2192.865 & 73 & & & \\
\hline
\end{tabular}

After two treatment sessions, post-test 1 was administered and participants were required to compose a writing with a different topic. The participants in the control group did not use any dictionary, but the participants in other groups used the dictionaries. Table 9 shows the results of one-way ANOVA for the scores of post-test 1. As it can be observed in Table 9, there is no statistically significant difference among the four groups on their post-test $1(F=.595, p=.621)$. 
Table 9

\begin{tabular}{|c|c|c|c|c|c|}
\hline & SS & $\mathrm{df}$ & MS & $\mathrm{F}$ & Sig. \\
\hline Between groups & 57.496 & 3 & 19.165 & .595 & .621 \\
\hline Within groups & 2255.868 & 70 & 32.227 & & \\
\hline Total & 2313.365 & 73 & & & \\
\hline
\end{tabular}

After two weeks interval, another ANOVA was run to the scores of post-test 2 which is provided in Table 10.

Table 10

One-Way ANOVA Results for the Post-Test 2 Scores of the Lexical Density

\begin{tabular}{lccccc}
\hline & SS & df & MS & F & Sig. \\
\hline Between groups & 5.130 & 3 & 1.710 & .082 & .970 \\
Within groups & 1461.532 & 70 & 20.879 & & \\
Total & 1466.662 & 73 & & & \\
\hline
\end{tabular}

Based on the results obtained from the one-way ANOVA for the post-test 2 scores, it can be concluded that there was no significant difference in the performance of all groups $(\mathrm{F}=.082$, $\mathrm{p}=.970)$.

\section{Discussion and conclusions}

Writing in language is one of the most important issues in second language teaching and learning. Particularly, in second language teaching (SLT), having good writing is highly important. To achieve such goals, many techniques have been tried but concerning this issue, one of the most important factors that has somehow been ignored is dictionary use. Whether L2 learners should be allowed to use dictionaries when writing in L2, has been the subject of debate for a good number of years. In the field of second language learning, a great deal of research has been conducted about dictionary use. To address this issue, a research question was posited in this study which is dealt with here in detail. It was asked if dictionary use affects Iranian EFL learners' lexical density or not. At the same time it has been highly important to find out which type of dictionaries was much more noticeable than the other. Considering the results and interpretations of the tests and the total score shown in the previous chapter, the research question can be answered now: Dictionary use does not affect EFL learners' lexical density. Based on the hypothesis of the study, it was expected that dictionary use would affect EFL learners' lexical density and the students who received dictionaries during writing sessions would outperform those who had not received dictionaries.

However, the results ran counter to the expectation and the hypothesis was rejected. Simply stated, the different types of dictionaries (including English to Persian, Persian to English and English to English dictionaries) do not have any significant role in EFL learners' lexical density. It is noteworthy that participants were able to perform equally well with or without the dictionary and the construct validity was not threatened. The findings of this study are along with those of some studies which reported that the use of dictionary cannot help the learners improve their 
writing (e.g., East, 2007; Bensoussan, Sim\& Weiss, 1984). East (2007) investigated the effect of dictionary use on the quality of L2 test takers' writings. The most important finding of this study was that the availability of bilingual dictionary made no significant difference to 'with dictionary' writing in comparison with 'without dictionary'. He also believed that the dictionary did not appear to make any difference to the tests as reliable measures of the construct of writing proficiency. In another study, Bensoussan, Sim and Weiss (1984) attempted to discover whether use or non-use of dictionary had an effect on students' performance on EFL reading and writing tests. They concluded that, when given the choice, participants preferred to use bilingual dictionaries, however, the use of dictionaries had no significant effect on students' test scores.

What was found here in this study stands in contrast to the results of the studies done by some other researchers (e.g., Karbalaei \& Talebi, 2011; Khosravi \& Roohani, 2011; Maghsoudi, 2010; Matsumoto \& Prichard, 2011; Prichard, 2008; Tono, 2000, and Weigle, 2002). They believed that using different types of dictionaries affected learners' reading comprehension and writing ability differently. It would be advantageous to talk over one of the above-mentioned studies. As an example, Karbalaei and Talebi (2011) investigated the effect of monolingual and bilingual dictionary and a comparison of their effect on reading comprehension of undergraduate ESL students. Their results revealed that in comparison to control group, using monolingual and bilingual dictionaries caused an effect on reading comprehension of the students in experimental group who were trained how to apply dictionary during reading and writing.

Although, there is not a significant difference between the performance of the four groups in this study, a slight improvement in the three experimental groups could be seen. Nevertheless, there might be some other influential factors. This study was conducted to pre-intermediate students and they were somehow novice in English. Perhaps, the results of the study could be different with other levels of participants. Various factors such as time, level of proficiency and experience, context of situation, age of learners and etc were involved in this study. Bearing all these factors in mind, the results of the study would be justified as follows. One interesting point was the participants themselves. Unexpectedly, they were not motivated in some cases since English was not their major. Furthermore, as East (2008) stated, low proficient participants could not take more benefit from dictionaries. He also claimed that one important benefit for having the dictionary in the writing test was that the dictionary helped test takers to find the right words for their context. Moreover, dictionaries made a psychological effect on the participants, that is to say, they were available when the participants got stuck. Having the dictionary contributes to a reassuring sense of security and comfort, whether it is used or not (East, 2008).

To sum it up, some L2 instructors force students to make use of their dictionaries as much as possible while others let them not to use a dictionary at all. Nevertheless, it would be beneficial for the learners to use dictionaries when writing and reading. At the very least, the results of the current study revealed that PED group (Persian to English Dictionary) proved more useful than EPD (English to Persian Dictionary) and EED groups (English to English Dictionary). 


\section{Implications of the study}

The findings emerging from this study have pedagogical implications for teachers, writers, students, syllabus designers, teacher educators, researchers, and instruction development. First, learners of English as a foreign language should learn how to use dictionary effectively. So, effort should be put on raising their awareness of potential benefits of employing useful strategies.

Weigle (2002, as cited in East, 2008) proposes that two potential liabilities to having a dictionary in a writing examination are the time taken to use a dictionary and some test takers' inability to use the dictionary effectively. The findings of his study regarding the total amount of time used to access the dictionary mirrored good points. First, on average test takers used the dictionary for around $20 \%$ of the available time. Using the dictionary during the study, did seem to help the participants to use the dictionary marginally more efficiently. Put it another way, it was not possible to determine if this was due to a kind of 'practice effect', or was a reflection of task types that the participants were asked to do. Nevertheless, if practice effect with the dictionary made the difference, however slight, it revealed that practicing dictionary use in time-constrained contexts might be helpful in alleviating the potential distraction of using a dictionary in such contexts.

In conclusion, the findings of this paper offer students an explicit understanding of how to use dictionary when writing and reading, in other words, when, how and what to look up in a dictionary. For teachers, not only address the needs of EFL writers but also draws them into new perspectives about dictionary use. It's hoped that this study will prove some insights to the teachers to make the students aware of different ways of using a dictionary. Additionally, teachers should know that the way to use a dictionary depends on the specific tasks that learners are engaged in.

\section{Avenues for further research}

Even though, a lot of effort was made to remove design and analytic flaws, there were some small limitations that must be considered when further research is planned. The contradictory results and mixed findings across classroom and experimental studies call for future research in classroom contexts. Thus, what is needed is subsequent studies that investigate the acquisition of features that learners have not yet begun to acquire, so, such research is lacking. This study explored only one level of participants, so more research is needed with regard to other levels of participants, particularly advanced level is suggested. As Matsumoto and Prichard (2011) put it, the efficacy of dictionary use depends on a number of factors, especially participants' vocabulary level. So, there is a strong need for further studies in this regard. In addition, the need is felt for extending the treatment sessions to a larger period of time so that the maximum effectiveness of dictionary can be determined.

Future studies might also aim at investigating some other uses. To name a few, using the dictionary for confirmation and clarification, for pronunciation, and new use of old words. The use of a dictionary for these reasons shows learners' concern for language form. Paying attention to the new use of old words by consulting a dictionary reveals the learners' active method toward the learning of language. Another issue which comes to mind is electronic dictionary. Although 
empirical research of electronic dictionary use is still in its infancy, it is also a very promising research area. Further research could dramatically improve the potential of electronic dictionaries for language learners. Finally, more studies are needed to elucidate the phenomenon of using the dictionary. In sum, the complex picture presented here is sufficient to suggest further research on the above issue.

\section{References}

Asher, C. (1999). Using dictionaries in the GCSE examination of modern foreign languages: Teachers' views and learners' performance. Studies in Modern Language Education, 7, 59-67.

Bachman, L. F., \& Palmer, A. S. (1996).Language testing in practice: Designing and developing useful language tests. Oxford, UK: Oxford University Press.

Barnes, A., Hunt, M., \& Powell, B. (1999). Dictionary use in the teaching and examining of MFLs at GCSE. Language Learning Journal, 19, 19-27.

Bensoussan, M., Sim, D \& Weiss, R. (1984). The effect of dictionary usage on EFL test Performance compared with student and teacher attitudes and expectations. Reading in a Foreign Language, 2(2), 262-276.

Bilton, L., \& Sivasubramaniam, S. (2009). An enquiry into expressive writing: A classroom- based study. Language Teaching Research, 13, 301-320.

Bishop, G. (2000). Dictionaries, examinations and stress. Language Learning Journal, 21, 2-65.

Bitchener, J., \& Knoch, U. (2010). Raising the linguistic accuracy level of advanced L2 writers with written corrective feedback. Journal of Second Language Writing, 19, 207-217.

Bitchener, J., Young, S. \& Cameron, D. (2005). The effect of different types of corrective feedback on ESL student writing. Journal of Second Language Writing, 14, 191-205.

Bogaards, P. (1998). Using dictionaries: Which words are looked up by foreign language learners? In B. T. S. Atkins \& K. Varantola (Eds), Studies of Dictionary Use by Language Learners and Translators, 151-157.

Bruton, A. (2007). Vocabulary learning from dictionary referencing and language feedback in EFL translational writing. Language Teaching Research, 11, 413-431.

Bruton, A. (2010). Another reply to Truscott on error correction: Improved situated designs over statistics. System, 38, 491-498.

Carter, R., \& Nunan, D. (2001).Teaching English to speakers of other languages. United Kingdom: Cambridge University Press.

Chambers, G. (1999). Using dictionaries in the GCSE examination of modern foreign languages-pupils' perceptions. Studies in Modern Language Education, 7, 68-85.

Chandler, J. (2003). The efficacy of various kinds of error feedback for improvement in the accuracy and fluency of L2 student writing. Journal of Second Language Writing, 12, 267-296.

East, M. (2007). Bilingual dictionaries in tests of L2 writing proficiency: Do they make a difference? Language Testing, 24(3), 331-353.

East, M. (2008).Dictionary use in foreign language writing exams. USA: John Benjamins.

Ellis, R. (2008). A typology of written corrective feedback types. ELT Journal, 10, 1-11.

Evans, W. N., Hartshorn, J. K., \& McCollum, M. R. (2010). Contextualizing corrective feedback in second language writing pedagogy. Language Teaching Research, 14(4), 445-463.

Ferris, D. R. (2003).Response to student writing. London: Lawrence Erlbaum Associates, Inc. 
Ferris, D. R. (2004). The "grammar correction" debate in L2 writing: Where are we, and where do we go from here? (And what do we do in the meantime . . . ?). Journal of Second Language Writing, 13, 49-62.

Ferris, D. R. (2010).Second language writing research and written corrective feedback in SLA. Studies in Second Language Acquisition, 32, 181-201.

Flynn, N. \& Stainthorp, R. (2006).The learning and teaching of reading and writing. England: Whurr Publishers.

Fung, M. Y. (2010). Collaborative writing features. RELC Journal, 41(1), 18-30.

Grabe, W. (2003).Reading and writing relations: Second language perspective on research and practice. Cambridge: Cambridge University Press.

Guénette, D. (2007). Is feedback pedagogically correct? Research design issues in studies of feedback on writing. Journal of Second Language Writing, 16, 40-53.

Hedge, T. (2000). Teaching and learning in the language classroom. Oxford: Oxford University Press.

Henrichs, L. F. (2010). Academic language in early childhood interactions: A longitudinal study of 3-to 6-year-old Dutch monolingual children. Amsterdam: University of Amsterdam (UAV). Retrieved from http://www.dare.uva.nl/document/168243.

Hunt, A., \& Beglar, D. (2005). A framework for developing EFL reading vocabulary. Reading in Foreign Language, $17,1-31$.

Hurman, J., \& Tall, G. (1998).The use of dictionaries in GCSE modern foreign languages written examinations (French). Birmingham, UK: University of Birmingham School of Education.

Hyland, k. (2003).Second language writing. United Kingdom: Cambridge University Press.

Ilson, R. (Ed.). (1985). Dictionaries, lexicography and language learning. Oxford, UK: Pergamon Press.

Kaplan, B. R. (Ed.). (2002). The Oxford handbook of applied linguistics. USA: Oxford University Press.

Karbalaei, A., \& Talebi, H. (2011). Assessing the effect of utilizing monolingual and bilingual dictionary on reading comprehension of ESL learners. American Journal of Scientific Research, 23, 22-34.

Khosravi, A., \& Roohani, A. (2011). An investigation into bilingual dictionary use: Do the frequency of use and type of dictionary make a difference in L2 writing performance. The Journal of Teaching Language Skills, 3(2), 85106.

Kirkness, A. (2004).Lexicography. In A. Davies \& C. Elder (Eds.).The handbook of applied linguistics (pp. 54-81). Oxford, UK: Blackwell.

Lalande, J. (1982). Reducing composition error: An experiment. Modern Language Journal, 66, 140-149.

Laufer, B., \& Hadar, L. (1997). Assessing the effectiveness of monolingual, bilingual and "bilingualized" dictionaries in the comprehension and production of new words. Modern language Journal, 81(2), 189-196.

Llach, M. P. A. (2011). Lexical errors and accuracy in foreign language writing. Britain: Channel View Publications.

Lu, X. (2012). The relationship of lexical richness to the quality ESL learners' oral narratives. The Modern Language Journal, 96(2), 190-208.

Maghsoudi, M. (2010). Type of task and type of dictionary in incidental vocabulary acqusition. The Asian EFL Journal Quarterly, 12(1), 313-336.

Matsumoto, Y., \& Prichard, C. (2011). The effect of lexical coverage and dictionary use on L2 reading comprehension. The Reading Matrix, 11(3), 207-225.

Mehrdad, G. A. (2008). The effect of dialogue journal writing on EFL students' writing skill. The Journal of Applied Linguistics, 1, 34-44.

Nation, I. S. P. (2009). Teaching ESL/EFL reading and writing. New York: Routledge.

O'Loughlin, K. (1995). Lexical density in candidate output of direct and semi-direct versions of an oral proficiency test. Language Testing, 12, 217-237. 
Paulus, T. M. (1999). The effect of peer and teacher feedback on student writing. Journal of Second Language Writing, $8,265-89$.

Prichard, C. (2008). Evaluating L2 readers' vocabulary strategies and dictionary use. Reading in a Foreign Language, 11(1), 151-168.

Thompson, G. (1987). Using bilingual dictionaries. ELT Journal, 41(4), 282-286.

Thonney, T. (2011).Teaching the conventions of academic discourse. TETYC, 1, 347-362.

Tono, Y. (2000). On the effects of different types of electronic dictionary interfaces on L2 learners' reference behavior in productive/receptive tasks. Electronic Dictionaries in Second Language Comprehension, 2, 855-861.

Truscott, J. (1996). The case against grammar correction in L2 writing classes. Language Learning, 46, 327-369.

Truscott, J. (2004). Evidence and conjecture on the effects of correction: A response to Chandler. Journal of Second Language Writing, 13, 337-343.

Truscott, J. (2007). The effect of error correction on learners' ability to write accurately. Journal of Second Language Writing, 16, 255-272.

Tuzi, F. (2004).The impact of e-feedback on the revisions of L2 writers in an academic writing course. Computers and Composition, 21, 217-35.

Ure, J. (1971). Lexical density and register differentiation. In G.E. Perren and J.L.M Trim (Eds). Applications of linguistics. Cambridge: Cambridge University Press.

Weigle, S. C. (2002). Assessing writing. Cambridge, UK. Cambridge University Press. Retrieved from http://www.books.google.com/books/frontcover/onepage.

Wiggins, G. (1989). A true test: Towards more authentic and equitable assessment. Phi Delta Kapan, 70, $703-713$.

$\mathrm{Xu}, \mathrm{X}$. (2010). Study on the effect of dictionary use on second language incidental vocabulary acquisition. An empirical study of college English vocabulary learning strategy. Journal of Language Teaching and Research, 1(4), 519-523. 